\title{
Avaliação do método de ensino da técnica cirúrgica utilizando cadáveres quimicamente preservados*
}

Evaluation of the surgical technique teaching method using chemically preserved cadavers

Evaluación del método de enseñanza de la técnica quirúrgica utilizando cadáveres químicamente preservados

Rosane Maria Guimarães da Silva'; Julia Maria Matera²; Antônio Augusto Coppi Maciel Ribeiro $^{3}$

Disciplinas de Técnica Cirúrgica e Ortopedia do Departamento de Cirurgia da Faculdade de Medicina Veterinária e Zootecnia da Universidade de São Paulo. São Paulo, SP, Brasil 


\section{Resumo}

Objetivo: Avaliar o treinamento cirúrgico em cadáveres quimicamente preservados oferecido pelas Disciplinas de Técnica Cirúrgica e de Ortopedia, da Faculdade de Medicina Veterinária e Zootecnia da Universidade de São Paulo (FMVZ/USP), São Paulo, SP, como método alternativo ao uso de animais vivos em aulas. Material e Método: Utilizou-se a Solução de Larssen modificada, que preserva as características dos animais como cor, consistência e textura dos tecidos e flexibilidade das articulações o mais semelhante possível às encontradas no animal vivo. Os cadáveres com peso corpóreo entre 1 e $25 \mathrm{~kg}$, com sexo e raças variáveis, foram higienizados e receberam uma lavagem do circuito vascular com solução fisiológica aquecida e uma segunda lavagem com Solução de Larssen modificada num volume correspondente a $5 \%$ do peso corpóreo do cadáver. Em uma segunda etapa, procedeu-se à injeção do fixador, cujo volume correspondeu a $10 \%$ do peso do cadáver. Após a fixação, os cadáveres foram criopreservados em câmara frigorífica com temperaturas de $-20^{\circ} \mathrm{C} \mathrm{a}-16^{\circ} \mathrm{C}$. A aceitação do uso de cadáveres como método de ensino foi avaliada por meio de questionário de pesquisa de opinião distribuído aos alunos que cursaram a disciplina de Técnica Cirúrgica nos anos de 2001, 2002 e 2003. Resultados e Conclusões: Pelas respostas ao questionário foi possível concluir que o método de ensino descrito é bem aceito pelos alunos. O uso de cadáveres quimicamente preservados com Solução de Larssen modificada permite treinamento intenso e adequado das técnicas cirúrgicas realizadas durante a disciplina. Tal prática possibilita a utilização dos cadáveres, várias vezes, diminuindo assim o número de animais necessários para as aulas.

Palavras-chave: Cirurgia veterinária, educação. Materiais de ensino. Bem-estar animal, ética. Cadáver. Alternativas para o uso de animais. Soluções para preservação de órgãos. Congelamento. Criopreservação. Avaliação.

\section{Introdução}

A utilização de cadáveres é um método de ensino amplamente realizado em diferentes escolas de veterinária em todo o mundo ${ }^{1}$.

O aproveitamento de cadáveres de animais que vêm a óbito nos hospitais veterinários, abrigos e centros de controle de zoonoses para o treinamento de técnicas cirúrgicas nas faculdades de veterinária contribui para acabar com a eutanásia para fins didáticos e possibilita o treinamento intenso dos alunos ${ }^{2}$. Outros estudos mostram que o uso de cadáveres durante o programa laboratorial de cirurgia realizado pelos alunos, quando suplementado com treinamento clínico adicional, pode promover treinamento comparável àquele realizado nos programas de laboratório convencionais ${ }^{3,4}$.

Tratando-se de treinamento cirúrgico, é necessário que o cadáver mantenha características como cor, consistência dos tecidos e flexibilidade o mais semelhante possível das encontradas em animais vivos.

Assegurar um número suficiente de cadáveres para o treinamento necessário requer planejamento cuidadoso e estocagem por longo prazo; o congelamento é uma solução. A preparação cuidadosa antes do congelamento, tal como a retirada do sangue, remoção de pêlos e colocação rápida no freezer pode ajudar no sucesso da preservação dos tecidos ${ }^{5}$. A manutenção de cadáveres em baixas temperaturas nas câmaras frigoríficas é citada como um método bom e antigo para a conservação e posterior dissecação ${ }^{6,7}$. $\mathrm{O}$ trabalho conjunto de áreas como anatomia e cirurgia permite uma melhor preservação dos cadáveres e conseqüentemente um ensino de qualidade ${ }^{1}$.

O método de ensino proposto no presente artigo inclui o treinamento inicial em cadáveres quimicamente preservados seguido por cirurgias realizadas em cães e gatos em campanhas de castração. $\mathrm{O}$ presente estudo 

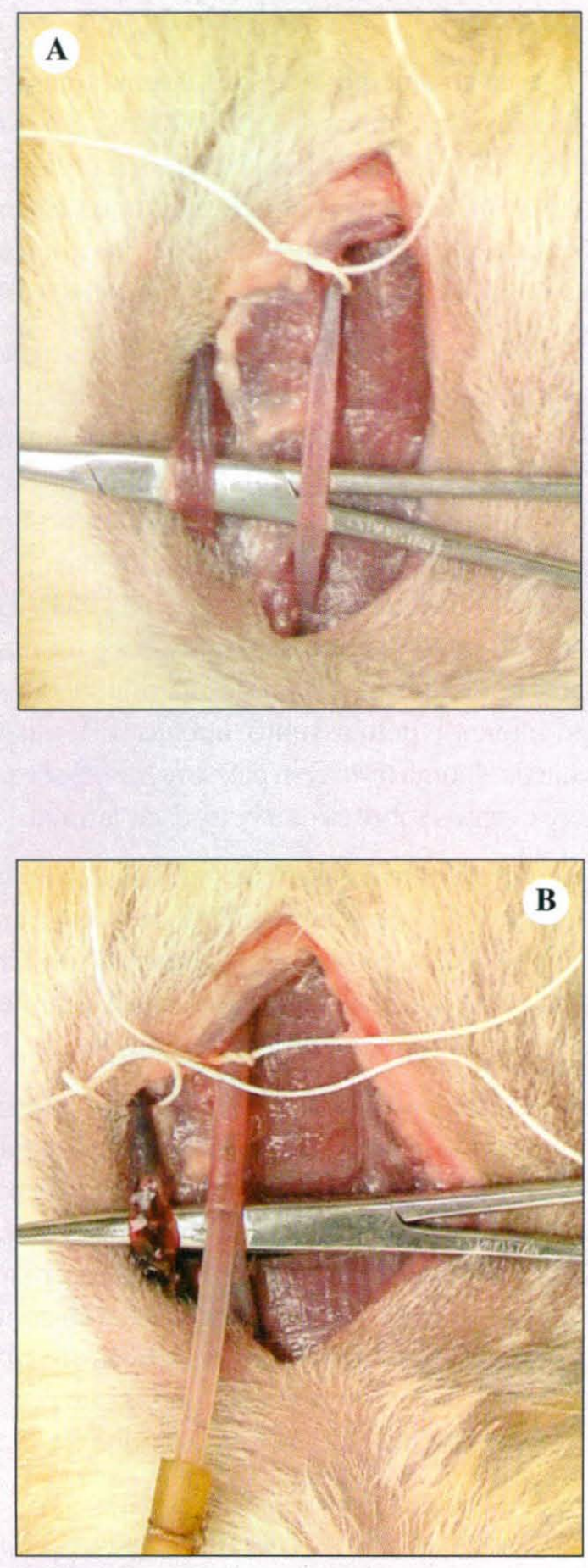

Figura 1 - Procedimento de fixação de cadáver de cão com solução de Larssen modificada: A Veia jugular externa e artéria carótida comum dissecadas; B - Extravasamento de sangue pela veia jugular externa durante a lavagem do circuito vascular com solução fisiológica. Artéria carótida canulada teve por objetivo avaliar a aceitação do método de ensino proposto para as disciplinas de Técnica Cirúrgica e Ortopedia, analisando a opinião dos alunos de graduação do curso de Medicina Veterinária da Faculdade de Medicina da Universidade de São Paulo (FMVZ/USP), São Paulo, SP. Além disso procurou aproveitar cadáveres de animais que vêm a óbito no Hospital Veterinário da FMVZ/USP (HOVET), por meio de técnicas de conservação que preservem suas características organolépticas e possibilitem a utilização prolongada deste material, reduzindo assim o número de animais necessários para as aulas.

\section{Material e Método}

A solução conservadora escolhida, aqui nomeada solução de Larssen modificada, baseou-se na fórmula do líquido de Larssen, utilizada pelo Serviço de Anatomia Patológica do Hôpital Cochin, da Universidade René Descartes, Paris V, França ${ }^{8}$. Para o preparo da solução-mãe foram utilizados: 100 $\mathrm{ml}$ de formalina a $10 \%, 400 \mathrm{ml}$ de glicerina líquida, 200 g de hidrato de cloral, 200 g de sulfato de sódio, $200 \mathrm{~g}$ de bicarbonato de sódio, $180 \mathrm{~g}$ de cloreto de sódio, $2000 \mathrm{ml}$ de água destilada. A diluição utilizada foi de uma parte da solução-mãe para três partes de água destilada.

Foram utilizados cadáveres com peso corpóreo entre 1 e $25 \mathrm{~kg}$, com sexo e raças variáveis provenientes do HOVET/ FMVZ/USP e do Centro de Controle de Zoonoses de São Paulo, São Paulo, SP.

O procedimento de higienização do cadáver incluiu a retirada de ectoparasitas, a limpeza do pêlo e da pele para retirar sujidades. A lavagem de seus orifícios naturais e o esvaziamento do trato intestinal foram executados através de jato de água pela via retal. Foi realizada uma lavagem do circuito vascular com injeção de solução fisiológica aquecida pela artéria carótida comum e extravasamento pela veia jugular externa, e uma segunda lavagem, pelas mesmas vias, com a Solução de Larssen modificada num volume correspondente a $5 \%$ do peso corpóreo do cadáver (Figura 1). 
Após a drenagem de líquido pela veia jugular, o fluxo foi interrompido por ligadura e iniciou-se o procedimento de injeção do fixador. O volume injetado nesta etapa correspondeu a $10 \%$ do peso do cadáver. Após a fixação, os cadáveres foram acondicionados em sacos plásticos, devidamente identificados e criopreservados em câmara frigorífica com temperatura de $-20^{\circ} \mathrm{C} \mathrm{a}-16^{\circ} \mathrm{C}$, onde foram mantidos suspensos por ganchos de ferro do tipo "S".

O descongelamento foi feito 24 horas antes da aula, em tanques com água. Os cadáveres foram utilizados para quatro aulas práticas com intervalo de pelo menos uma semana; no intervalo de cada utilização eram mantidos criopreservados em câmara frigorífica.

A aceitação do uso de cadáveres como método de ensino foi avaliada por intermédio de um questionário de pesquisa de opinião distribuído aos alunos que cursaram a disciplina de Técnica Cirúrgica nos anos de 2001, 2002 e 2003.

\section{Resultados e Discussão}

A disciplina de Técnica Cirúrgica entre 2001 e 2003, foi cursada por 230 alunos. Destes, $190(82,61 \%)$ responderam ao questionário de pesquisa de opinião sobre o método de ensino proposto.

Do total de alunos que respondeu ao questionário $93,29 \%$ foram a favor do método que inclui o treinamento inicial em cadáveres seguido de castrações em animais vivos e $84,79 \%$ consideraram que o conteúdo das aulas foi bem assimilado com o uso de cadáveres.

$\mathrm{O}$ treinamento intenso possibilitado pelo uso de cadáveres e a responsabilidade adquirida com as castrações em animais vivos foram os principais pontos positivos da disciplina citados pelos alunos.

Foi questionada a opinião dos alunos quanto ao uso de animais vivos nas diversas disciplinas do curso de medicina veterinária. O número de alunos favoráveis (84\% em média) foi superior em todas as turmas pesquisadas, tanto ao iniciar a graduação, quanto no $4^{\circ}$ ano do curso, quando esta pesquisa de opinião foi realizada. O número de alunos contrários ao fornecimento de animais vivos pelo CCZ para as faculdades de veterinária subiu de 25\%, em 2001, para 37,93\%, em 2003.

Um levantamento sobre posse de animais de estimação realizado nos anos de 2002 e 2003, verificou que $92 \%$ a $98 \%$ dos alunos têm ou já tiveram animais, sendo que mais de $60 \%$ por um período maior que 10 anos. $\mathrm{O}$ cão foi a espécie mais freqüente ( $83 \%$ dos alunos), seguida pelos felinos (35\%), aves (25\%) e peixes (15\%).

Para sensibilizar os colegas cientistas e todas as pessoas que trabalham com animais a respeito das questões éticas e de bem-estar animal, em primeiro lugar, deve vir a "educação", que pode ser adquirida por meio de palestras sobre ética, bem-estar, métodos alternativos, aprimoramento e intercâmbio de conhecimentos ${ }^{9}$. Os alunos da disciplina de Técnica Cirúrgica da FMVZ/USP foram questionados sobre essas questões e foi possível constatar que, embora $100 \%$ dos estudantes de 2003 tenham interesse pelo assunto, apenas $33 \%$ disseram participar de alguma forma em palestras, discussões, campanhas e eventos sobre ética e bem-estar animal.

O crescimento do interesse pelo assunto foi percebido quando $84 \%$ dos alunos de 2003 responderam que deveria constar como obrigatória no currículo do curso de veterinária a disciplina de Ética e Bem-Estar Animal. Em 2001, essa era a opinião de $65 \%$ dos alunos.

Levantar essas questões durante uma pesquisa de opinião como a que foi idealizada para este trabalho pode ser uma maneira de fazer os alunos pensarem a respeito da utilização de animais em ensino e pesquisa. É possível que esses alunos, no futuro, tornem-se professores, formadores de opinião, e que darão continuidade à discussão sobre as questões éticas envolvidas no uso de animais nas universidades e que por meio deles, sejam desenvolvidos novos métodos alternativos de ensino.

Alguns educadores acreditam na necessidade do uso de animais vivos para que os estudantes de veterinária conheçam as expectativas do cliente envolvidas no uso desses animais nos laboratórios de cirurgia ${ }^{3}$. Na FMVZ/USP, três dos docentes que ministram aulas de Técnica Cirúrgica (60\%) consideraram que os cadáveres fixados com Solução de Larssen modificada permitiram treinamento intenso e satisfatório. Um do- 


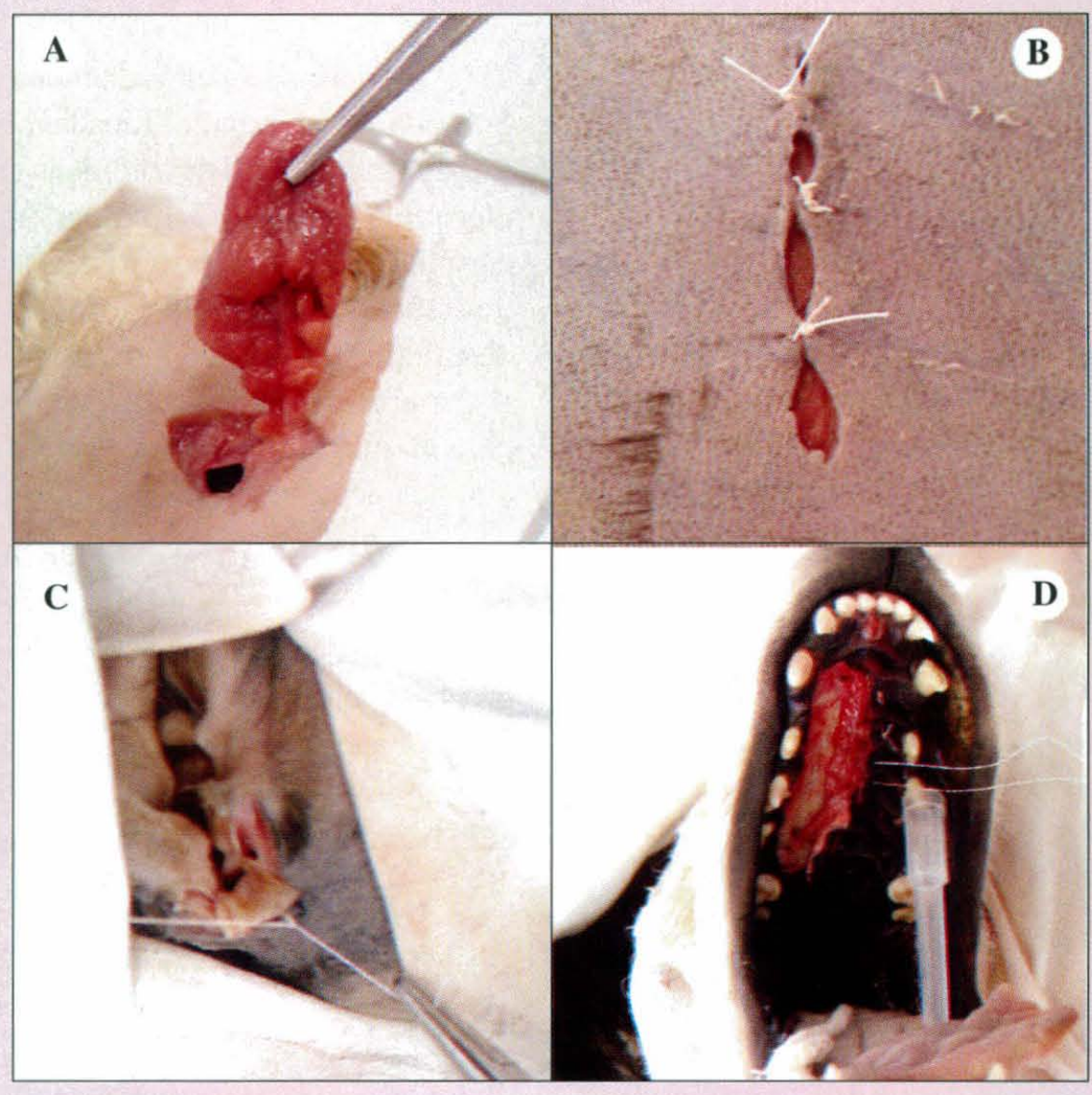

Figura 2 - Procedimentos cirúrgicos realizados pelos alunos em cadáveres preservados com solução de Larssen modificada: A - Ressecção de glândula salivar mandibular e sublingual; B - Incisão e sutura da pele através da técnica de elipse; C - Ressecção do canal vertical da orelha; D - Técnica de correção de fenda palatina

cente considerou que o treinamento não foi adequado e outro que estes cadáveres não são adequados para alguns procedimentos, como esplenectomia e enterotomia.

As escolas de veterinária têm procurado associar o treinamento em cadáveres à prática em animais vivos no atendimento dos hospitais veterinários ${ }^{3,4}$. Os alunos precisam desse contato com a realidade e a responsabilidade de acompanhar o pós-operatório dos animais e aprender a lidar com as expectativas dos proprietários. Os alunos de Técnica Cirúrgica da FMVZ/USP confirmaram a importância desse contato com o proprietário ao citarem, em todas as turmas avaliadas nesta pesquisa, a responsabilidade adquirida com as cirurgias de castrações como um dos principais pontos positivos de tal matéria. A inclusão da campanha de esterilização no programa da disciplina teve $97,30 \%$ de aprovação pelos alunos entrevistados.

A associação entre treinamento em cadáveres e castrações em animais vivos foi o método de ensino escolhido por $91 \%$ dos alunos avaliados no presente estudo, em 2003, confirmando as afirmações de outros autores sobre a eficácia da complementação do uso de cadáveres com a prática cirúrgica em animais $\operatorname{vivos}^{3,4}$. 
A solução fixadora utilizada na presente pesquisa, denominada Solução de Larssen modificada e desenvolvida a partir da solução descrita por Sampaio ${ }^{8}$, em 1989, mostrou-se adequada para os propósitos de garantir aos alunos um material muito semelhante ao que encontrariam no animal vivo, no que diz respeito à coloração, à consistência de tecidos e livre de odor de putrefação (Figura 2).

Do total de alunos que respondeu ao questionário $86 \%$ trabalharam mais de uma vez com o mesmo animal. Desses alunos, $62 \%$ consideraram bom usar os mesmos cadáveres nas aulas, citando que isto, além de não influenciar no aprendizado das técnicas cirúrgicas, diminui o número de animais necessários.

Durante as aulas, os alunos desenvolveram seu treinamento em cadáveres com a mesma seriedade com que realizaram as cirurgias nos animais vivos e acompanharam o pós-operatório desses pacientes.

\section{Conclusões}

Os cadáveres quimicamente preservados com a Solução de Larssen modificada mostraram-se adequados ao treinamento das técnicas cirúrgicas propostas em aula. Tal solução, ao ser injetada pela artéria carótida, é capaz de preservar no cadáver a coloração dos tecidos, a flexibilidade das articulações e evitar o desprendimento de odor característico de putrefação. A criopreservação em câmara frigorífica é necessária para manter a integridade dos tecidos dos cadáveres quimicamente preservados.

O método de ensino proposto foi aceito pelos alunos da graduação tanto para a disciplina de Técnica Cirúrgica como para a de Ortopedia. O método proposto pela disciplina de Técnica Cirúrgica, por meio das orquiectomias e ovariosalpingohisterectomias em animais vivos realizadas pelos alunos, também contribui para o controle populacional de cães e gatos.

\section{Abstract}

Objective: To assess surgical training in chemically preserved cadavers in the classes of Surgical Technique and Orthopedics of "Faculdade de Medicina Veterinária e Zootecnia da Universidade de São Paulo" (College of Veterinary Medicine and Zootechny from University of São Paulo) - (FMVZUSP), São Paulo, SP, Brazil, as an alternative method to use of live animals in classrooms. Material and Method: A modified Larssen solution that preserves the characteristics of animals color, consistency and texture of tissues and flexibility of joints as similar as possible to those found in live animal was used. Cadavers with body weight between 1 and $25 \mathrm{~kg}$, different sexes and races were cleaned and received a lavage of the vascular circuit with hot physiologic solution and a second lavage with modified Larssen solution at a volume corresponding to 5\% of the cadaver body weight. At a second stage, fixing solution was injected whose volume corresponded to $10 \%$ of cadaver weight. After fixation, cadavers were cryopreserved in cold chambers with temperatures of $-20^{\circ} \mathrm{C}$ to $-16^{\circ} \mathrm{C}$. Acceptance of use of cadavers as a teaching methodology has been assessed by means of a survey questionnaire distributed among students of Surgical Technique in 2001, 2003 and 2003. Results and Conclusions: From responses to questionnaires it was possible to conclude that the above described teaching methodology is well accepted by students. Use of cadavers chemically modified Larssen solution allows intense and adequate training of surgical techniques carried out along the course. Said practice allows the repeated use of cadavers, decreasing the number of animals needed for classroom purposes.

Keywords: Surgery. Veterinary. Teaching methods. Welfare animal. Ethics. Cadavers. Animal testing alternatives. Chemical preservation. Freezing techniques. Cryopreservation. Assessment. 


\section{Resumen}

Objetivo: Evaluar el entrenamiento quirúrgico con cadáveres químicamente preservados, ofrecido por las Disciplinas de Técnica Quirúrgica y Ortopedia de la Facultad de Medicina Veterinaria y Zootecnia de la Universidad de São Paulo (FMVZUSP), São Paulo, SP, Brasil, como método alternativo a la utilización de animales vivos en clase. Material y Método: Se utilizó una solución modificada de Larssen, que preserva las características de los animales como el color, la consistencia y la textura de los tejidos y la flexibilidad de las articulaciones lo más cercano posible a las características encontradas en el animal vivo. Los cadáveres con un peso corpóreo entre 1 y $25 \mathrm{~kg}$, de sexo y de razas variadas, fueron higienizados y recibieron un lavado del circuito vascular con una solución fisiológica calentada y un segundo lavado con una solución modificada de Larssen, cuyo volumen correspondiente al 5\% del peso corpóreo del cadáver. En una segunda etapa, se inyectó el fijador, cuyo volumen correspondió al $10 \%$ del peso del cadáver. Después de la fijación, los cadáveres fueron criopreservados en cámara frigorífica a temperaturas entre $-20^{\circ} \mathrm{C} y-16^{\circ} \mathrm{C}$. Se evaluó la aceptación del uso de cadáveres como método de enseñanza a través de una encuesta hecha a los alumnos que cursaron la disciplina de Técnica Quirúrgica en 2001, 2002 y 2003. Resultados y Conclusiones: Por las respuestas obtenidas en la encuesta se pudo concluir que el método de enseñanza descrito fue bien aceptado por los alumnos. El uso de cadáveres químicamente preservados con solución modificada de Larssen permite un entrenamiento intenso y adecuado de las técnicas quirúrgicas realizadas durante el curso. Esa práctica permite la utilización de los cadáveres, varias veces, disminuyendo así el número de animales necesarios para las clases.

Palabras-clave: Cirugía veterinaria, educación. Materiales de enseñanza. Bienestar del animal, ética. Cadáver. Alternativas de uso de animales. Soluciones preservantes de órganos. Congelamiento. Criopreservación. Evaluación.

\section{Referências}

1. GROSCURTH, P. et al. Gross anatomy in surgical curriculum in Switzerland: improved cadaver preservation, anatomical models and course development. Anatomical Record, v. 165, p. 254 256, 2001.

2. DUFFEE, N. Alternative training methods. 1. Laboratory Animal, v. 28, p. 32-36, 1999.
3. BAUER, M. S. A survey of the use of live animals, cadavers, inanimate models, and computers in teaching veterinary surgery. Journal of the American Veterinary Medical Association, v. 203, p. 1047-1051, 1993.

4. PAVletiC, M. M. et al. An assessment of the outcome of alternative medical and surgical 
laboratory program at Tufts University. Journal of the American Veterinary Medical Association, v. 205, n. 1, p. 97-100, 1994.

5. JUKES, N.; CHIUIA, M. From guinea pig to computer mouse: alternative methods for progressive humane education. 2. ed. Leicester: International Network for Humane Education InterNICHE, 2003. 520 p.

6. HOLMBERG, D. L. et al. Use a dog abdominal surrogate for teaching surgery. Journal of Veterinary Medical Education, v. 20, p.107-111, 1993.
7. SCHWEISTHAL, M. I. R. The use of fresh specimens in the gross anatomy laboratory. Anatomical Record, v. 160, p. 496, 1968.

8. SAMPAIO, F. J. B. Estudo do crescimento do rim humano durante o período fetal. 1989. Tese (Doutorado em Morfologia)-Escola Paulista de Medicina da Universidade Federal de São Paulo, São Paulo, 1989.

9. RIVERA, E. A. B. Ética na experimentação animal. In: ANDRADE, A. et al. Animais de laboratório: criação e experimentação. Rio de Janeiro: FIOCRUZ, 2002. p. 25-28. 